\title{
Internal Hernia Resulting in Bowel Obstruction After Laparoscopic Colectomy
}

\author{
Yasunori Yoshimoto, MD, PhD, Akira Tanaka, MD, PhD, Toshihiro Abe, MD, PhD, \\ Takahisa Fujikawa, MD, PhD, Norihiro Shimoike, MD, Seiichiro Tada, MD, \\ Hisatsugu Maekawa, MD, Mitsuo Nishiyama, MD \\ Kokura Memorial Hospital, Department of Surgery, Kitakyushu, Fukuoka, Japan (all authors).
}

\begin{abstract}
A 65-year-old woman underwent laparoscopic-assisted sigmoidectomy for management of sigmoid colon cancer. Her postoperative recovery was initially uneventful; however, on postoperative day 12 , the patient suddenly complained of abdominal pain. Further surgical intervention was finally performed on postoperative day 21 because conservative treatment had been unsuccessful in relieving the obstruction. Laparoscopic surgery revealed that a segment of the proximal jejunum had herniated through an orifice, forming an adhesion between the mesentery of the ileum and the incised retroperitoneum of the mesenteric opening. The obstruction was relieved by laparoscopic adhesiolysis. Only 7 cases have previously been reported where the mesenteric opening has caused an internal hernia resulting in bowel obstruction. This case may suggest the need for closure of the mesenteric opening to prevent this complication after laparoscopic colectomy; however, there is no consensus on whether a mesenteric opening should be closed. Further research is needed to identify the patients who would benefit from the closure of mesenteric defects during laparoscopic-assisted colectomy.
\end{abstract}

Key Words: Internal hernia, Laparoscopic surgery, Small-bowel obstruction.

Citation Yoshimoto Y, Tanaka A, Abe T, Fujikawa T, Shimoike N, Tada S, Maekawa H, Nishiyama M. Internal hernia resulting in bowel obstruction after laparoscopic colectomy. CRSLS e2014.00177. DOI: 10.4293/CRSLS.2014.00177.

Copyright $\odot 2014$ SLS This is an open-access article distributed under the terms of the Creative Commons Attribution-Noncommercial-ShareAlike 3.0 Unported license, which permits unrestricted noncommercial use, distribution, and reproduction in any medium, provided the original author and source are credited.

Address correspondence to: Yasunori Yoshimoto, MD, PhD, Kokura Memorial Hospital, Department of Surgery, 3-2-1, Asano, Kokura-kita, Kitakyushu, Fukuoka 802-8555, Japan. Telephone: (+81) 93-511-2000, Fax: (+81) 93-511-3240, E-mail: yyasu@wg8.so-net.ne.jp

\section{INTRODUCTION}

Laparoscopic-assisted colectomy (LAC) is now an established alternative to open colectomy. In general, the incidence of small-bowel obstruction (SBO) after LAC is said to be significantly lower than that after conventional open colectomy (OC). SBO is also a recognized complication that is not uncommon after LAC. However, little information exists regarding these complications, in particular, postoperative SBO caused by an internal hernia. We report a case of SBO caused by an internal hernia with a comparative rare orifice forming an adhesion between the mesentery of the ileum and the incised retroperitoneum of the mesenteric opening after laparoscopic-assisted sigmoidectomy.

\section{CASE REPORT}

A 65-year-old woman was consulted for further examination after a positive fecal occult blood test result. Colono- scopy and barium enema revealed a $30 \times 30-\mathrm{mm}$ protruding lesion in the sigmoid colon. Biopsies were performed, and the results confirmed well-differentiated adenocarcinoma. There were no significant abnormalities in the blood test, including tumor markers. In addition, obvious lymph node and distant metastases were not observed in the computed tomography (CT) examination. She underwent laparoscopic-assisted sigmoidectomy with lymph node dissection to the level of the inferior mesenteric artery (D3 lymph node dissection). A functional end-toend anastomosis was performed with linear staplers, before closing the incised mesocolon as much as possible. After temporarily sealing the minilaparotomy area using a surgical glove, we checked the anastomosis and the mesenteric opening laparoscopically and found no internal hernia. Although the closure between the incised mesocolon and the retroperitoneum was insufficient, it was not large enough to cause problems in the intestinal tract. Pathologic examination revealed cancer invading the 


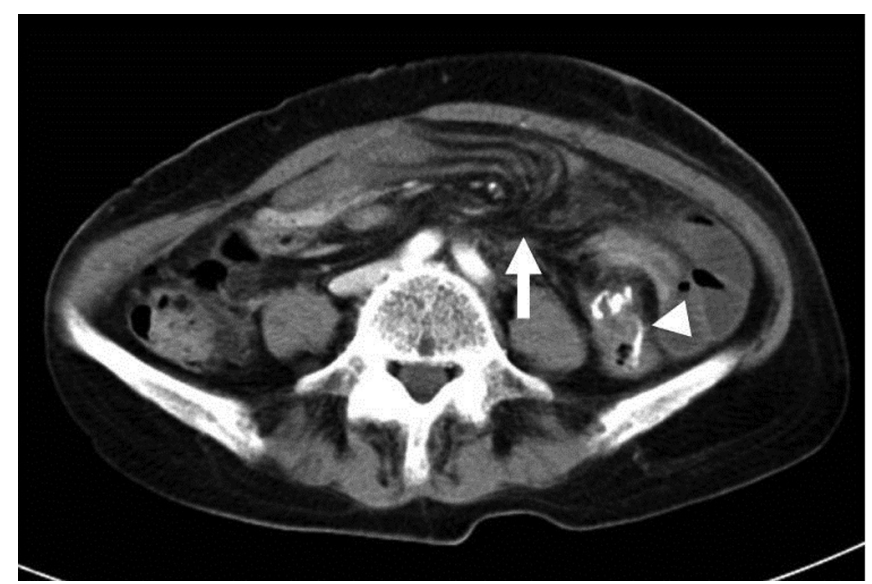

Figure 1. Computed tomography (A) on POD 14 showed converged, stretched, and engorged mesocolonic vessels (arrow) near the anastomotic segment (arrowhead) in the left upper abdomen.

muscularis propria but without lymph node metastasis. The final diagnosis was made as $\mathrm{S}$, type1, MP, ly0, v0, ow $(-)$, aw (-), NO, P0, H0, M0, stage 1 .

The patient's postoperative recovery was initially uneventful. On postoperative day (POD) 12, when she had planned to be discharged, the patient complained of sudden-onset abdominal pain and vomiting. The left upper abdomen was slightly distended, and tenderness was noted over the same area. Plain radiographic examination revealed air-fluid levels in the left upper quadrant. The patient's body temperature, vital signs, and blood test results were within normal limits. She was treated with bowel rest, nasogastric suction, and intravenous hydration, with the presumptive diagnosis of an adhesive SBO. Surgery was not chosen because her physical symptoms improved after decompression with nasogastric suction. Because the SBO did not fully resolve, CT examination was done on POD 14 and revealed converged, stretched, and engorged mesenteric vessels near the anastomotic segment in the left upper abdomen (Figure 1). On the basis that the diagnosis was SBO caused by an internal hernia, a long tube was inserted on POD 15, resulting in the immediate resolution of her radiographic findings. However, she complained of abdominal pain and distention on POD 19, and a CT scan showed that the SBO had developed despite the long-tube decompression.

On POD 21, surgical intervention was finally performed because conservative treatment was unsuccessful in relieving the obstruction. Laparoscopic intervention revealed that a segment of the proximal jejunum had herniated through an orifice caused by adhesions that had formed between the mesentery of the ileum and the in-
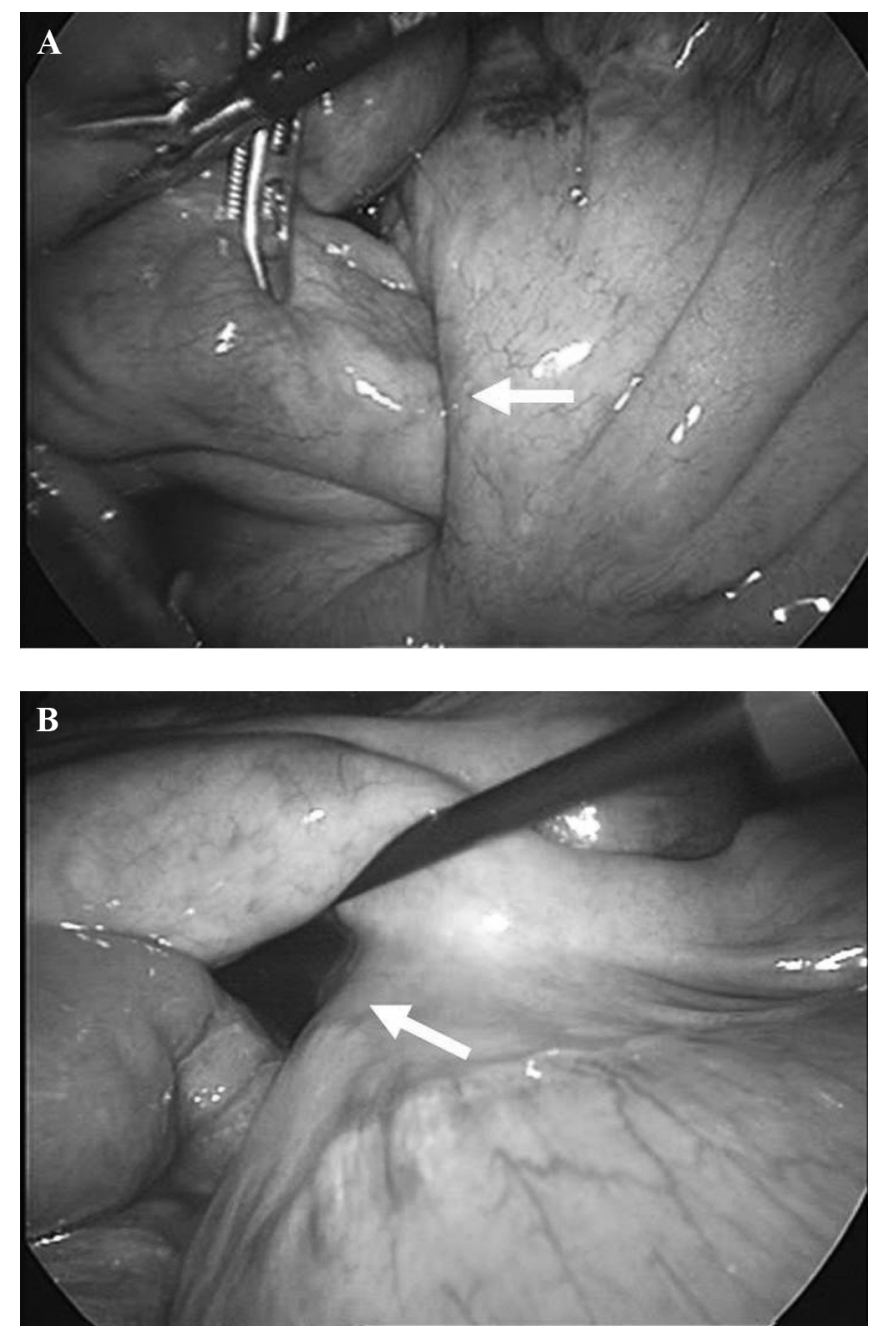

Figure 2. A and B, Laparoscopic findings showed that a segment of the proximal jejunum had herniated through the orifice (arrow), which was caused by the adhesion between the mesentery of the ileum and the retroperitoneum incision near the mesocolonic opening.

cised retroperitoneum of the mesenteric opening (Figure $\mathbf{2 A}$ and $\mathbf{B}$ ). The obstruction was relieved by laparoscopic adhesiolysis. The small bowel returned to its normal position, and despite the mesenteric opening being closely adherent to the retroperitoneum, there were no additional adhesions. The patient was discharged after an uneventful recovery. Follow-up at 5 years revealed no clinical or radiographic evidence of recurrence of the cancer or the internal hernia.

\section{DISCUSSION}

LAC is the surgical procedure of choice for treating colorectal cancer. According to the analysis by Schwenk et al 


\begin{tabular}{|c|c|c|c|c|c|c|c|c|}
\hline \multirow[b]{2}{*}{ Reference } & \multirow[b]{2}{*}{ Year } & \multirow[b]{2}{*}{ Age/Sex } & \multicolumn{4}{|c|}{$\begin{array}{l}\text { Table } \mathbf{1 .} \\
\text { Clinical Characteristics of Internal Hernia After LAC }\end{array}$} & \multirow[b]{2}{*}{$\begin{array}{l}\text { Procedure for Internal Hernia/ } \\
\text { Mesenteric Opening }\end{array}$} & \multirow[b]{2}{*}{ Outcome } \\
\hline & & & $\begin{array}{l}\text { Primary } \\
\text { Disease }\end{array}$ & $\begin{array}{l}\text { Initial Laparoscopic } \\
\text { Operation }\end{array}$ & $\begin{array}{l}\text { Interval/ } \\
\text { Operation }\end{array}$ & $\begin{array}{l}\text { Cause of Internal } \\
\text { Hernia }\end{array}$ & & \\
\hline Kok et $\mathrm{al}^{2}$ & 1996 & $64 / \mathrm{F}$ & S-cancer & S-resection & $3 \mathrm{mo} / 3 \mathrm{mo}$ & Mesenteric opening & Lap_adhesiolysis/unknown & Recovery \\
\hline Elio et $\mathrm{al}^{4}$ & 1998 & $46 / \mathrm{F}$ & D-adenoma & Left hemicolectomy & $2 \mathrm{mo} / 2 \mathrm{mo}$ & Mesenteric opening & Open-adhesiolysis/close & Recovery \\
\hline Kawamura et $\mathrm{al}^{7}$ & 1999 & $47 / \mathrm{F}$ & S-cancer & S-resection & $20 \mathrm{~d} / 26 \mathrm{~d}$ & Mesenteric opening & Open—adhesiolysis/close & Recovery \\
\hline Nagata et als & 2005 & $55 / \mathrm{F}$ & T-cancer & T-resection & $5 \mathrm{~d} / 15 \mathrm{~d}$ & Mesenteric opening & Open-adhesiolysis/close & Recovery \\
\hline Hosono et $\mathrm{al}^{5}$ & 2007 & $58 / \mathrm{F}$ & T-cancer & T-resection & $7 \mathrm{~d} / 7 \mathrm{~d}$ & Mesenteric opening & $\begin{array}{l}\text { Open-partial resection of } \\
\text { jejunum/close }\end{array}$ & Recovery \\
\hline Jimi et $\mathrm{al}^{6}$ & 2007 & $68 / \mathrm{F}$ & A-cancer & Right hemicolectomy & $59 \mathrm{~d} / 59 \mathrm{~d}$ & Mesenteric opening & $\begin{array}{l}\text { Open-ileo-transverse } \\
\text { colostomy/close }\end{array}$ & Recovery \\
\hline Matsubuchi et al9 & 2012 & $61 / \mathrm{F}$ & T-cancer & T-resection & $42 \mathrm{mo} / 42 \mathrm{mo}$ & Mesenteric opening & LAP_reintegration/close & Recovery \\
\hline Our case & & $65 / \mathrm{F}$ & S-cancer & S-resection & $12 \mathrm{~d} / 21 \mathrm{~d}$ & Ileum loop & LAP_adhesiolysis/close & Recovery \\
\hline
\end{tabular}

$\mathrm{S}$, sigmoid colon $\mathrm{D}$, descending colon $\mathrm{T}$, transverse colon $\mathrm{A}$, ascending colon $\mathrm{d}$, days mo, months

of 25 randomized controlled trials about the recognized benefits of LAC to colorectal resection, LAC has several advantages over OC. ${ }^{1}$ Complications most frequently reported after LAC are wound infection, leakage and anastomotic fistula, abdominal abscess, bowel obstruction, incisional and perineal hernia, and others. ${ }^{2}$ SBO is also a recognized complication that is not uncommon after LAC. A recent systematic review with meta-analysis showed that the incidence of bowel obstruction after LAC was significantly lower (1.7\%) than that after conventional OC $(4.6 \%){ }^{1}$ Although there are few data defining the incidence of hernia formation after LAC, Duepree et al have reported that the incidence of both ventral hernia and postoperative SBO after LAC (2.4\%) was significantly lower than that after OC (12.9\%). ${ }^{3}$ Most SBOs reported after LAC were caused by an incarcerated Richter hernia at the trocar site. SBO caused by internal hernia after LAC is comparatively rare. To the best of our knowledge, only 7 cases of SBO caused by internal hernia after LAC have been reported in the literature. ${ }^{1,4-9}$ The clinical characteristics of these cases are summarized in Table 1. In all cases except ours, the obstruction was caused by smallbowel loops incarcerating or herniating through the mesenteric opening. In our case, the hernial orifice was caused by an adhesion between the mesentery of the ileum and the incised retroperitoneum of the mesenteric opening that had been created by the medial approach. At the time of surgery, the mesocolonic opening had already closed and adhered to the retroperitoneum. The mesentery of the small intestine may have adhered during the process of adhesion.

Although SBO secondary to internal hernia after LAC is not a rare event, it involves significant morbidity in healthy patients after otherwise successful LAC. It is generally accepted that there is no need to close the mesenteric opening in cases of LAC, but cases such as these might suggest the need for complete closure of the mesenteric opening. This could help prevent the formation of an internal hernia that could result in SBO after LAC. It has been reported that a small mesenteric opening (eg, 5,6,8 If the mesenteric opening is large, the small bowel could displace freely through it. However, adhesions around the mesenteric opening may reduce its size, thereby increasing the risk of internal hernia. Although adhesions around the mesenteric opening could avoid small-bowel incarceration, these may form the hernial orifice, as was shown in our case. This suggests that closure of the mesenteric opening may at least aid in preventing the formation of an internal hernia resulting in SBO after LAC.

Closure of the mesenteric opening after bowel resection is sometimes difficult owing to the limited surgical space. Further development of the methods and devices used to attain the safe and easy closure of the mesenteric opening is still required. There are some useful reports about laparoscopic mesenteric closure. For example, continuous or interrupted suturing with absorbable threads and clips ${ }^{4}$ and incarceration with part of the greater omentum ${ }^{9}$ could be performed to prevent a mesenteric hernia after LAC.

Further studies will be required to resolve the dispute over whether we should seek closure of the mesenteric opening after LAC to prevent this complication.

The authors thank A.T., who provided helpful comments and suggestions, and T.A. and T.F., whose comments made an enormous contribution to the work. 


\section{References:}

1. Schwenk W, Haase O, Neudecker J, et al. Short term benefits for laparoscopic colorectal resection. Cochrane Database Syst Rev. 2005;3(3):CD003145.

2. Kok KY, Ngoi SS, Kum CK, et al. Laparoscopic-assisted large bowel resection. Ann Acad Med Singapore. 1996;25:650-652.

3. Duepree HJ, Senagore AJ, Delaney CP, et al. Does means of access affect the incidence of small bowel obstruction and ventral hernia after bowel resection? Laparoscopy versus laparotomy. J Am Coll Surg. 2003;197:177-181.

4. Elio A, Veronese E, Frigo F, et al. Ileal volvulus on internal hernia following left laparoscopic-assisted hemicolectomy. Surg Laparosc Endosc. 1998;8:477-478.

5. Hosono S, Ohtani H, Arimoto $\mathrm{Y}$, et al. Internal hernia with strangulation through a mesenteric defect after laparoscopyassisted transverse colectomy: report of a case. Surg Today. 2007;37:330-334.
6. Jimi S, Hotokezaka M, Eto TA, et al. Internal herniation through the mesenteric opening after laparoscopy-assisted right colectomy: report of a case. Surg Laparosc Endosc Percutan Tech. 2007;17:339-341.

7. Kawamura YJ, Sunami E, Masaki T, et al. Transmesenteric hernia after laparoscopic-assisted sigmoid colectomy. JSLS. 1999; 3:79-81.

8. Nagata K, Tanaka J, Endo S, et al. Internal hernia through the mesenteric opening after laparoscopy-assisted transverse colectomy. Surg Laparosc Endosc Percutan Tech. 2005;15:177-179.

9. Masubuchi S, Okuda J, Tanaka K, et al. An internal hernia projecting through a mesenteric defect following laparoscopicassisted partial resection of the transverse colon to the lesser omental cleft: report of a case. Surg Today. 2012. Epub ahead of print. 